\title{
A capability approach for online primary and secondary students with disabilities
}

Julie Stella, Michael Corry

\section{Abstract}

A capability approach was used to identify and synthesize research studies about online students with disabilities in primary and secondary school (aged five to 18 years) in an attempt to describe the experience from an empirical perspective. A capability approach is intended to maximize agency and can be used to describe the extent to which individuals are able to use limited resources to build a satisfying and enjoyable life. In this analysis, a derived capability set was used to narrow the larger body of research about primary and secondary students in online education in order to consider only studies that described ways in which students successfully used online education to maximize agency. The derived capability set was: autonomy, judgement, practical reason, affiliation, high school graduation and a desire to help others. A method for deriving the capability set and ways in which a capability approach fails to describe this experience are discussed.

\section{Keywords}

Online education, distance education, online learning, capability approach, primary and secondary

This is the author's manuscript of the article published in final edited form as:

Stella, J., \& Corry, M. (2017). A capability approach for online primary and secondary students with disabilities. British Journal of Special Education, 44(4), 448-464. https://doi.org/10.1111/1467-8578.12187 


\section{Introduction}

As online education becomes more readily available and accessible, it is important to understand how students with disabilities in primary and secondary school (aged five to 18 years) can use this delivery method in their learning experiences. One way to examine this issue is through the lens of a capability approach. A capability approach has great potential to add evaluative knowledge to the domain of research about primary and secondary students with disabilities in online education. The capability approach was first proposed by Amartya Sen in the mid-1980s as a theory of global economic development, and scholars have since extended it as a theoretical framework to describe various socially constructed groups in terms of equity and access. A capability approach is intended to maximize human agency, and it is used to describe the extent to which individuals are able to build for themselves a satisfying and enjoyable life. Equity and access in online education has been examined thoroughly by researchers prior to 2004 (Greer et al., 2014) but whether students with disabilities are able to maximize their agency and build for themselves a satisfying and enjoyable life using the resources of online education is not clear. Online education for students at college and university level is relatively common, but it remains an innovative practice that has not yet been explored in detail at the primary and secondary level; as such, many additional philosophical questions remain about online education for primary and secondary students with disabilities: whether online education is inclusive/exclusive, whether online education encourages/discourages equality of agency in students, what are the best practices in this field, and many more.

\section{Sen's capability approach: theory}

A capability approach attempts to quantify the fundamentally meaningful human desire for freedom, especially freedom of choice, which can lead to satisfaction and overall well-being. A capability approach seeks to maximize freedom by maximizing an individual's capability set. A capability set is a set of all possible things a person can do and be in a society, given the available resources. In other words, individuals in a society have access to resources, which they can convert into a set of capabilities. From a capability set of all possibilities, a person chooses functionalities. Functionalities are what a person chooses to do and be. If a capability set is large, a person has more freedom to choose, which maximizes overall satisfaction and well-being.

A capability approach focuses more on what a person can do with their life rather than what commodities they can buy with their income; as such, it is less about equality and more about reducing inequality. It does not address distribution of resources (as in a Rawlsian approach); instead, it recognizes variation among individuals, while demanding better outcomes for all. In other words, a person's individual choice of what a 'satisfying and enjoyable life' entails matters less than the fact that he/she has a maximum number of equally desirable ways to live that life. Although capability maximization under this approach is inherently personal and individual, it is usually discussed as a collective index, or used as a way to comment on the development opportunities in a population (Sen, 1985).

\section{Sen's capability approach: practice}

Sen was purposely ambiguous about the actual contents of a capability set and a defined set of human functionings, which has made a capability approach difficult in practical/operational application. Regardless, many scholars are pragmatists as well as theorists, and the interest in applying a capability 
approach continues, though some scholars believe it does not have practical or operational possibilities. The difficulties in applying it are many, including: (a) the theory leans heavily on valuation, human diversity and objectivity; and (b) measuring agency is challenging because observable evidence about an individual reflects his/her choices (functionings), but we cannot know how many other things (s)he could have been (Comim, 2001).

Practitioners can resolve the difficulty in valuation by defining a core set of human capabilities (to be well-sheltered, to be nourished, etc.). Other difficulties of objectivity and measuring agency are less easily resolved, and human diversity, of course, is unavoidable in societal groups (Comim, 2001; Sen, 1985).

Despite the apparent difficulties with creating a practical way to apply the capability approach, interest in quantifying the human experience in some way based on values, diversity, objectivity and unobservable evidence appears to remain strong (see the World Happiness Index, Ibrahim Index of National Governance, the Foster-Greer-Thorbecke Index, and others). Even so, theorists advise against seeking exact answers (Comim, 2001; Sen, 1993).

\section{Sen's capability approach: example}

Although Sen's capability approach was intentionally vague when it was introduced, it has since been used in a variety of practical ways (for example, Biggeri \& Karkara, 2014; Comim, 2001; Davidson, 2015; Norwich, 2014; Unterhalter, 2009). Practitioners generally begin by delimiting a social domain and generating a list of capabilities associated with that domain. After that, the list of capabilities can be used as a lens through which to evaluate the domain itself or interrogate existing research in the domain. For example, in an analysis of gender equality in Western societies, Robeyns (2003) created a list of possible capabilities by combining capabilities about gender inequality, which had been proposed by several well-known scholars. The list of possible capabilities was used to extrapolate a set of 10 nonredundant capabilities, which was then used to evaluate published research in the domain of gender equality in Western societies. In a similar way, this analysis investigated the work of three education theorists (Saito, Nussbaum and Terzi) in order to derive a capability set with which to analyze the domain of research about primary and secondary students with disabilities in online education.

\section{Saito}

In 2003, Saito suggested applying a capability approach to education because education can enable individuals to develop resources into income, but that is not its only value. Indeed, education is associated with public well-being, freedom of individuals, ability to influence social change and ability to influence economic production - in addition to generating income. Saito suggested the capabilities specific to education are autonomy and judgement.

Autonomy is a capability that can be realized when education provides life opportunities that a child may have never thought possible. For example, an educated child may come to know mathematics, which opens opportunities for her to become a mathematician, physicist, teacher or scientist. The opportunities lead to careers which students can eventually choose through the capability of autonomy.

In considering judgement as a capability, Saito questioned whether the capability approach applied to children (whose agency is limited). After all, education can create capabilities that lead to immoral functionality, such as when a child develops the capability of physical strength through education and 
uses this capability to hurt other children. Saito concluded that educationally supported capabilities are neutral, but judging their use as good or bad is another capability that can be developed with education. Thus, the capability of judgement becomes crucial because it adds morality to the model.

\section{Nussbaum}

In 2001, Nussbaum extended the capability approach by defining a list of central human capabilities (life, bodily integrity, senses/imagination/thought, emotion, practical reason, affiliation, other species, play, and control over one's environment). Later, Nussbaum evaluated this list and selected capabilities that applied specifically to education. Nussbaum considered practical reason and affiliation the most important because they define what it is to be uniquely human and can be used in the development of all other capabilities.

\section{Terzi}

Terzi (2005) applied the capability approach as an effort to resolve a consistent theoretical conundrum in special education, the dilemma of difference. The dilemma of difference is the unavoidable choice between identifying and noting children's differences in order to provide for their unique needs in education and emphasizing their sameness to prevent labelling. A capability approach can resolve the sides of this argument by describing children's differences relationally. If a relational continuum of students with differences was delimited by impairment and disability, then a child's disability would depend wholly on supports in the school environment (where resources are constrained by time and economic reality). In a capability approach, a relationship exists between a child's impairment and the social world of school and home, but disability remains undefined as long as capabilities are maximized for an individual. This is a subtle, yet important distinction in online education for students with disabilities because it raises the question of what role the mode of delivery plays in 'manufacturing' disability.

A capability approach based on a relational continuum also addresses the natural variation among students. In other words, it seeks to reduce inequities in education caused by variations such as socialeconomic status, race, ethnicity, gender (and others), while supporting the natural variance of talents and abilities among students by emphasizing equality of agency. Therefore, a lens of education for all students based on a capability approach: (a) must set a threshold of capabilities to be enabled for all students by education; and (b) suggests that those who can grow capabilities beyond the threshold must develop high achievement, which should be used to benefit those achieving at a lower level.

\section{Summary}

The non-redundant capability set culled from the writing of Saito, Nussbaum and Terzi was:

- autonomy;

- judgement;

- practical reason;

- affiliation;

- achieving a threshold of capability for functioning in society (high school graduation);

- nurturing a desire to help others. 
In the analysis that follows, the capability set was used to organize and synthesize research in the domain of online education for students with disabilities.

\section{Analysis of the domain}

A capability approach seeks to evaluate equality of agency, which is a uniquely important individual right for students with disabilities. As such, this analysis, using a capability approach as a lens, should not be considered a comprehensive review of the research domain. Instead, the analysis focused on empirical research studies and reviews, which evaluate one or more of these capabilities in online education at the primary and secondary level: autonomy and good judgement, practical reason and affiliation, preparation for higher education/employment and service learning in education. Thought pieces and articles denoting recommendations for teaching and learning with disabilities online, though important to the field, were not included in this analysis. In addition, the analysis has considered only research published after 2004 because the studies prior to 2004 focused primarily on equal access/opportunity, not equal agency (Greer et al., 2014). In addition, studies that focused solely on achievement would not be considered because a capability approach evaluates whether an individual is able to build for himself/herself a satisfying and enjoyable life, which differs notably from achievement (Sen, 1993; Comim, 2001).

\section{Research about autonomy and good judgement (Saito)}

Academic autonomy and good judgement are under development in primary and secondary students, and deficits in these areas can clash with the relative freedom offered students in an online environment (Lewis et al., 2014). Some research results suggest that it is the autonomous nature of online education that has contributed to high attrition rates (Barbour \& Reeves, 2009; Cavanaugh et al., 2009); however, it may also be true that online education offers a unique opportunity for students to develop autonomy and good judgement in their learning.

One way the online environment might be particularly suited to the development of autonomy is through opportunities to exercise freedom of choice. Research has long suggested that student autonomy can be increased through student self-determination which, when executed properly, provides opportunities for choice in education (Algozzine et al., 2001; Test et al., 2005; Wehmeyer et al., 2004). The most basic expression of autonomy and freedom of choice for students with disabilities in online education is, of course, whether they decide to pursue it; the answer seems clear - parents of students, not the students themselves, most often make this choice. In a 2013 (Harvey et al., 2014) survey of 119 parents of online students with disabilities, results indicated that in the case of $88 \%$ of students educated fully online, the parent made the placement decision. The same survey indicated that the student made the placement decision in $31 \%$ of cases for fully online students. Though the parent and student may both have favoured online education, it is not clear the extent to which a student was able to exert agency in the decision process, as students with disabilities are often under subtle pressures from caregivers and society, which can hinder their agentic expression (Wehmeyer \& Garner, 2003).

Online writing instruction for adolescent students may offer a unique perspective into autonomy. Writing is a solo task, but it is inherently communicative; thus, the self-expression and self-regulation that students learn in writing practice is a social experience (Schunk \& Zimmerman, 2007). A recent study of high school students with learning disabilities and their experience in an online writing class is 
worth noting in this context (Straub \& Vasquez, 2015). In the study, the students produced writing using a synchronous online collaborative writing technology, which was intended to support self-regulated strategy development in writing. The synchronous technology allowed tutors to oversee the student writing process, which is usually solitary, and intervene to support students in the planning phase of writing. Students also produced collaborative writing, which allowed tutors to evaluate self-expression and self-regulation skills. The study had only four students, but all improved their outcomes in some way. It is not clear, however, whether students in this study were able to generalize the self-regulation strategies they learnt through writing toward autonomy and good judgement, but the researchers did note that the online environment seemed particularly suited to students with disabilities.

Similar to the way that autonomy is linked to self-determination, so is the development of good judgement, which can be especially important for students with disabilities. Research about developing the capabilities of autonomy and good judgement in online education for students in higher education is relatively plentiful (Means et al., 2009), but it is less so in online education at the primary/secondary level and even less in online education for students with disabilities. It is known, however, that relatively positive educational outcomes are achieved for students with disabilities through immersion in a classroom of peers (Beck, Egalite \& Maranto, 2014; Harvey et al., 2014; Hipsky \& Adams, 2008); therefore, researchers must ask whether the benefits of autonomous learning, the ability to make choices in educational activities and the development of decision-making skills outweigh the lack of immersion with one's peers.

\section{Research about practical reason and affiliation (Nussbaum)}

According to Nussbaum (2001), practical reason and affiliation are the two capabilities that allow a child truly to grow and flourish in life; therefore, they are among the basic capabilities students must develop in education. Practical reason in a capability approach may be viewed broadly as a way to expand choices for students. Affiliation in a capability approach may be more narrowly defined as social skills, which can be easier to quantify.

Practical reason is defined by Nussbaum (2001, p. 79) as 'Being able to form a conception of the good and to engage in critical reflection about the planning of one's life'. While the ability to conceive of the good in one's life is somewhat ambiguous, planning is more concrete. If the good in life can be equated with student satisfaction, many studies showed results that suggested students with disabilities were equally or more satisfied with their online education than they had been in their prior experiences with face-to-face education (Beck, Egalite \& Maranto, 2014; Smouse, 2005). Parents are satisfied as well (Burdette \& Greer, 2014). In one study of students and parents, results suggested that the well-being of students with disabilities in online education was even greater than it was for their non-disabled peers (Beck, Egalite \& Maranto, 2014). Despite these positive results, however, more research must be done about high attrition rates in online education and whether they are related to a lack of satisfaction with online education for students with disabilities.

Students with disabilities sometimes struggle with practical skills such as planning and life-management, which are crucial for their success in future employment or higher education. Research studies about face-to-face education programmes that offer a transition-planning curriculum for students with disabilities are plentiful, but such programmes are not always available in online education. In 2013 , a study by Spitler et al. was published, which reported on a successful transition-planning programme in 
an online school. The researchers evaluated the success of a pedagogical framework, which was considered to be particularly supportive of students with disabilities. The school's curriculum included instruction in life skills, such as meal preparation and counting money, which instructors taught via Web camera. The chief executive officer of the school reported positive outcomes for students with disabilities at the school.

Additional studies of online intervention applications, which teach planning and life-management skills, seem promising for students with disabilities. They are not considered fully online education courses, but their success is still notable. Positive results have been noted in the successful use of iPads to facilitate the connection between home and school (Dixon et al., 2015) and to learn time-management skills, such as list-making (Stephenson, 2015). Another successful programme teaches the multi-faceted skill of shopping for groceries. In this programme, students with disabilities are able to make note of mistakes in the lower-stress classroom environment before trying out their skills in an actual supermarket (Goo et al., 2016).

Whether students with disabilities are able to transform the resource of online education into affiliation may be evaluated in capabilities related to social skills. Not surprisingly, one of the most frequently asked questions in online education is whether students become isolated and poorly socialized when attending school online, and the research findings are mixed. Some research studies suggest that negative social experiences are a root cause of a student's choice to attend school online (Ahn, 2011; Beck, Egalite \& Maranto, 2014; Beck, Maranto \& Lo, 2014; Sorensen, 2012), but other studies report very few social issues (Thompson et al., 2012). Teachers, parents and students have noted ways that online education may uniquely support the development of social competence in students through its ability to emphasize individual student strengths instead of exacerbating weaknesses; however, as is true for all students, this may depend on individual differences, which vary greatly in students with disabilities (Shattuck et al., 2012).

A recent case study (Johnston et al., 2014) of young students with disabilities (aged seven, 11 and 12) illustrates the impact of individual differences. The study took place in a fully online school. Participants consisted of a random sample of students from the school roster, their parents, their teachers and school administrators. All were interviewed on two separate occasions. From the interview transcripts, researchers discovered that none of the students participated significantly in peer-to-peer learning, even though the teachers modelled the practice often. According to the researchers, the results suggested that participation was mediated by learner variability, design variability and context variability. Learner variability was demonstrated in the way students with learning disabilities naturally varied in their ability to participate in social learning. Design variability was demonstrated in the way virtual environments vary in affordances that support online education for students with disabilities. Context variability is found in the wide variety of curriculum available for students with disabilities at the primary and secondary level. The conclusion about individual differences was also supported in a research review by Ray and Attwill (2004).

Many research studies present results in which online education was used as a tool to teach a specific skill for students with disabilities. Indeed, research studies documenting the successful use of the online environment as a simulative space are plentiful (Means et al., 2009). The simulative environment may be especially helpful in teaching social skills to students with disabilities in its ability to offer a safe place to learn from mistakes and try new skills. In addition, teachers are better able to monitor student 
behaviour in a virtual classroom because text and audio/video are recorded; therefore, they may be better able to monitor individual social situations. These social advantages in an online environment could relieve a considerable amount of stress for students with disabilities (Hipsky \& Adams, 2008).

\section{Research about preparation for higher education/employment and service learning in education (Terzi)}

Graduation from high school is a threshold of capability associated with maximizing positive life outcomes of effective functioning in society (Heckman \& LaFontaine, 2010). Whether students in online education can convert resources into a high school diploma is a complex question for all students, especially those with disabilities (Archambault et al., 2010; Barth et al., 2012; Pape et al., 2007; Schnase, 2011; Schwirzke, 2011, Weston, 2009). Some students with disabilities, many of whom are considered at-risk students, have used online education to recover credits and graduate with their cohort; while others have returned to school online and graduated later (Archambault et al., 2010; Burdette \& Greer, 2014; Spitler et al., 2013). The ability to use online education in this way may be limited, however, as at least one major research effort, a dissertation by Schnase (2011), found that credit deficiency was the only independent variable significantly correlated with high school graduation. Many researchers and practitioners recommend increased support for students in online education to prevent dropout, while other researchers suggest that the unique qualities of the online education experience are especially supportive of success for online students with disabilities (Allday \& Allday, 2011; Spitler et al., 2013; Vasquez \& Straub, 2012).

Increased graduation support in the form of an engagement framework designed to increase graduation rates (called ' 5 Cs') was studied in a cyber charter school with 3,353 students. An analysis of data from textual sources and interviews suggested that success in the school's special education programme could be attributed to the framework. Many other researchers have validated the $5 \mathrm{Cs}$ approach since (Repetto et al., 2010). Individualized pacing and flexibility in the online environment have also been found to be supportive of course completion, and higher final grades as well (Allday \& Allday, 2011). Some researchers have suggested that the support of non-technologically-based affordances in online education, such as the freedom to move freely about the learning area while pursuing online education or the ability to record and replay class meetings, is especially valuable to students with disabilities (Beck, Egalite \& Maranto, 2014; Beck, Maranto \& Lo 2014; Lewis et al., 2014; Smouse, 2005; Spitler et al., 2013; Straub \& Vasquez, 2015), even though some still struggle with higher-order learning skills, such as expository writing (Okolo et al., 2011). Overall, evidence is strong for the online environment as a particularly supportive mode of education for students with disabilities; however, questions remain about individual differences.

Whether students with disabilities are able to convert resources into a desire to help others through online education is an open question. At least one online high school requires a service-learning project as part of its graduation requirements, and research reports about community/school collaborations in online education at the primary and secondary level have been published by respected sources, such as the International Association for Online Learning (Watson, 2007; Wicks, 2010); however, no studies have been published on the service-learning experience for students with disabilities. Perhaps an alternative way students with disabilities can nurture a desire to help others may be through contributions to public stores of knowledge, such as wikis and blogs, but the research on their use is lacking for students at the primary and secondary level (perhaps due to privacy concerns). Collaboration with other students, 
however, is a practice for which research about these students can be investigated. One research study, which asked specifically about collaboration, found that adolescent students, especially, are affected by their peers' efforts in collaborating as well as befriending, motivating and instructing in online education (Borup, 2016). This finding aligns with research evidence about the growing influence of peers at this age, which has been documented in neuroscience research about social-cognitive and affective development for children (Crone, 2009; Crone \& Dahl, 2012; Konrad et al., 2013). Combined with other studies that note a lack of collaborative opportunities for students with disabilities in online education (Johnston et al., 2014), the acknowledgement that these students especially benefit from social interactions with peers (Stichter et al., 2014) suggests that further study of collaboration as a pedagogical tool may be a fruitful avenue of future research. This conclusion is also supported by the work of Straub and Vasquez (2015).

\section{Where does the capability approach fail to describe the experience?}

A capability approach to online education for students with disabilities has strengths and weaknesses. One of its strengths is an ability to suggest that researchers focus on those aspects in the lives of students that are most likely to help them create for themselves a satisfying and enjoyable life. A capability approach also emphasizes equality in agency rather than equality of opportunity, which is especially important in online education because it is a particularly agentic process. The main weakness of a capability approach in this situation is similar to its weaknesses in other analyses in the domain of welfare economics (Biggeri \& Karkara, 2014; Comim, 2001; Davidson, 2015; Norwich, 2014; Unterhalter, 2009) - it provides no definition of causes of inequity. Researchers of online education for students with disabilities may also question whether a special individual education plan (IEP) process should be in place for students with disabilities in online education because some parts of the traditional IEP do not transfer to online education (for example, preferential seating in a classroom), and students probably need supports unique to online education. As well, it is clear that individual regions of the world implement online education for students with disabilities unevenly (Burdette \& Greer, 2014; Greer et al., 2014).

\section{Conclusion}

It remains to be seen whether students with disabilities are uniquely abled in online education to convert resources to capabilities, and a capability approach may help us understand their position. The landscape of resources available for students in online education is vast, with increased use of education technology, affordances in software, Universal Design for Learning, assistive technologies, online spaces, virtual relationships, avatars, video and more; however, despite high satisfaction rates, it remains to be seen whether outcomes are consistently more positive for students with disabilities. As such, whether online education has the unique ability to emphasize more prominently the positions of strength in students with disabilities instead of exacerbating weaknesses is yet unknown. We are just beginning to understand better how online learning can be used to benefit students with disabilities. In the future, additional research directed at this issue using a capability approach is recommended so that educational policy makers and practitioners may better understand the best uses of online learning as a tool for success. Using this increased understanding and its application, students with disabilities may benefit from online learning opportunities and maximize their agency while building a satisfying and enjoyable life. 


\section{Authors}

Julie Stella, Michael Corry

Address for correspondence:

Julie Stella

George Washington University - Graduate School of Education and Human Development

2134 G. Street NW

Washington DC 20052

USA

Email: juliestella@gwu.edu 


\section{References}

Ahn, J. (2011) 'Policy, technology, and practice in cyber charter schools: framing the issues', Teachers College Record, 113 (1), 1-26.

Algozzine, B., Browder, D., Karvonen, M., Test, D. W. \& Wood, W. M. (2001) 'Effects of interventions to promote self-determination for individuals with disabilities', Review of Educational Research, 71 (2), 219-277.

Allday, C. M. \& Allday, R. A. (2011) 'Effects of pacing options on final grades of students with disabilities in virtual high school', Quarterly Review of Distance Education, 12 (4), 223.

Archambault, L., Diamond, D., Brown, R., Cavanaugh, C., Coffey, M., Foures-Aalbu, D., Zygouris-Coe, V. \& Richardson, J. (2010) 'Research committee issues brief: an exploration of at-risk learners and online education'. Vienna, VA: International Association for K-12 Online Learning.

Barbour, M. K. \& Reeves, T. C. (2009) 'The reality of virtual schools: a review of the literature', Computers \& Education, 52 (2), 402-416.

Barth, P., Hull, J. \& St Andrie, R. (2012) 'Searching for the reality of virtual schools'. Alexandria, VA. Center for Public Education, National School Boards Association [online at http://www.centerforpubliceducation.org/Main Menu/Organizing-a-school/Searching-for-thereality-of-virtual-schoolsat-a-glance/Searching-for-the-reality-of-virtual-schools-full-report.pdf].

Beck, D., Egalite, A. \& Maranto, R. (2014) 'Why they choose and how it goes: comparing special education and general education cyber student perceptions', Computers \& Education, 76, 7079.

Beck, D. E., Maranto, R. \& Lo, W. J. (2014) 'Determinants of student and parent satisfaction at a cyber charter school', Journal of Educational Research, 107 (3), 209-216.

Biggeri, M. \& Karkara, R. (2014) 'Transforming children's rights into real freedom: a dialogue between children's rights and the capability approach from a life cycle perspective', in D. Stoecklin and J.M. Bonvin (eds), Children's Rights and the Capability Approach. Dordrecht: Springer.

Borup, J. (2016) 'Teacher perceptions of learner-learner engagement at a cyber high school', International Review of Research in Open and Distributed Learning, 17 (3), DOI: https://doi.org/10.19173/irrodl.v17i3.2361.

Burdette, P. J. \& Greer, D. L. (2014) 'Online learning and students with disabilities: parent perspectives', Journal of Interactive Online Learning, 13 (2), 67-88.

Cavanaugh, C. S., Barbour, M. K. \& Clark, T. (2009) 'Research and practice in K-12 online learning: a review of open access literature', International Review of Research in Open and Distributed Learning, 10 (1), DOI: https://doi.org/10.19173/irrodl.v10i1.607.

Comim, F. (2001) 'Operationalizing Sen's capability approach'. Paper prepared for Justice and Poverty: Examining Sen's Capability Approach Conference, Cambridge, 5-7 June.

Crone, E. A. (2009) 'Executive functions in adolescence: inferences from brain and behavior', Developmental Science, 12 (6), 825-830.

Crone, E. A. \& Dahl, R. E. (2012) 'Understanding adolescence as a period of social-affective engagement and goal flexibility', Nature Reviews Neuroscience, 13 (9), 636-650.

Davidson, A. L. (2015) 'A collaborative action research about making self-advocacy videos with people with intellectual disabilities', Social Inclusion, 3 (6), DOI: https://doi.org/10.17645/si.v3i6.412.

Dixon, R. M., Verenikina, I., Costley, D. \& Pryor, S. (2015) 'The use of iPads in the home setting for students with autism spectrum disorders', Journal of Special Education Technology, 30 (4), 193206.

Goo, M., Hua, Y. \& Therrien, W. J. (2016) 'Effects of computer-based video instruction on the acquisition and generalization of grocery purchasing skills for students with intellectual disability', Education and Training In Autism and Developmental Disabilities, 51 (2), 150. 
Greer, D., Rice, M. \& Dykman, B. (2014) 'Reviewing a decade (2004-2014) of published, peer-reviewed research on online learning and students with disabilities', in Handbook of Research on $\mathrm{K}-12$ Online and Blended Learning. Pittsburgh, PA: ETC Press.

Harvey, D., Greer, D., Basham, J. \& Hu, B. (2014) 'From the student perspective: experiences of middle and high school students in online learning', American Journal of Distance Education, 28 (1), 1426.

Heckman, J. J. \& LaFontaine, P. A. (2010) 'The American high school graduation rate: trends and levels', Review of Economics and Statistics, 92 (2), 244-262.

Hipsky, S. \& Adams, L. (2008) 'Strategies for teaching students with exceptional needs in cyber schools', International Journal of Information and Communication Technology Education, 2 (4), 1-14.

Johnston, S. C., Greer, D. \& Smith, S. J. (2014) 'Peer learning in virtual schools', International Journal of ELearning \& Distance Education, 28 (1), DOI: 10.4018/jicte.2006100101.

Konrad, K., Firk, C. \& Uhlhaas, P. J. (2013) 'Brain development during adolescence', Deutsches Ärzteblatt International, 110 (25), 425-431.

Lewis, S., Whiteside, A. \& Dikkers, A. G. (2014) 'Autonomy and responsibility: online learning as a solution for at-risk high school students', Journal of Distance Education (Online), 29 (2), 1.

Means, B., Toyama, Y., Murphy, R., Bakia, M. \& Jones, K. (2009) Evaluation of Evidence-Based Practices In Online Learning: a metaanalysis and review of online learning studies. Washington DC: US Department of Education.

Norwich, B. (2014) 'How does the capability approach address current issues in special educational needs, disability and inclusive education field?', Journal of Research in Special Educational Needs, 14 (1), 16-21.

Nussbaum, M. C. (2001) Women and Human Development: the capabilities approach, vol. 3. Cambridge: Cambridge University Press.

Nussbaum, M. C. (2011) Creating Capabilities. Cambridge, MA: Harvard University Press.

Okolo, C. M., Englert, C. S., Bouck, E. C., Heutsche, A. \& Wang, H. (2011) 'The virtual history museum learning US history in diverse eighth grade classrooms', Remedial and Special Education, 32 (5), 417-428.

Pape, L., Revenaugh, M., Watson, J. \& Wicks, M. (2006) 'Measuring outcomes in K-12 online education programs: the need for common metrics', Distance Learning, 3 (3), 51.

Pape, L., Revenaugh, M. \& Wicks, M. (2007) 'Measuring outcomes in K-12 online programs: the need for common metrics.' Paper presented at $23^{\text {rd }}$ Annual Conference on Distance Teaching \& Learning, Madison, WI.

Ray, L. \& Atwill, K. (2004) 'The web and special education', Computers in the Schools, 21 (3-4), 53-67.

Repetto, J., Cavanaugh, C., Wayer, N. \& Liu, F. (2010) 'Virtual high schools: improving outcomes for students with disabilities', Quarterly Review of Distance Education, 11 (2), 91.

Robeyns, I. (2003) 'Sen's capability approach and gender inequality: selecting relevant capabilities', Feminist Economics, 9 (2-3), 61-92.

Saito, M. (2003) 'Amartya Sen's capability approach to education: a critical exploration', Journal of Philosophy of Education, 37 (1), 17-33.

Schnase, L. P. (2011) 'The virtual classroom: a quantitative study of online education and high school graduation.' PhD thesis, Capella University.

Schunk, D. H. \& Zimmerman, B. J. (2007) 'Influencing children's self-efficacy and self-regulation of reading and writing through modeling', Reading \& Writing Quarterly, 23 (1), 7-25.

Schwirzke, K. L. (2011) Online Learning in California K-12 Schools: status and perceptions of administrators. ProQuest LLC.

Sen, A. (1985) Commodities and Capabilities. Oxford: Oxford University Press. 
Sen, A. (1993) 'Capability and well-being', in M. Nussbaum and A. Sen, The Quality of Life. Oxford: Oxford University Press.

Shattuck, P. T., Narendorf, S. C., Cooper, B., Sterzing, P. R., Wagner, M. \& Taylor, J. L. (2012) 'Postsecondary education and employment among youth with an autism spectrum disorder', Pediatrics, 129 (6), 1042-1049.

Smouse, T. L. (2005) 'Students with either specific learning disabilities or with attention deficit hyperactivity disorder: perceptions of self as learner in online courses at Florida Virtual School and in the traditional learning environment.' PhD thesis, University of Central Florida.

Sorensen, C. (2012) 'Learning online at the K-12 level: a parent/guardian perspective', International Journal of Instructional Media, 39 (4), 297-308.

Spitler, C., Repetto, J. \& Cavanaugh, C. (2013) 'Investigation of a special education program in a public cyber charter school', American Journal of Distance Education, 27 (1), 4-15.

Stephenson, J. (2015) 'Teaching schedule use on an ipad to children with developmental disabilities', Journal of Special Education Technology, 30 (4), 207-212.

Stichter, J. P., Laffey, J., Galyen, K. \& Herzog, M. (2014) 'iSocial: delivering the social competence intervention for adolescents ( $\mathrm{SCl}-\mathrm{A})$ in a 3D virtual learning environment for youth with high functioning autism', Journal of Autism and Developmental Disorders, 44 (2), 417-430.

Straub, C. \& Vasquez, E. (2015) 'Effects of synchronous online writing instruction for students with learning disabilities', Journal of Special Education Technology, 30 (4), 213-222.

Terzi, L. (2005) 'Beyond the dilemma of difference: the capability approach to disability and special educational needs', Journal of Philosophy of Education, 39 (3), 443-459.

Test, D. W., Fowler, C. H., Wood, W. M., Brewer, D. M. \& Eddy, S. (2005) 'A conceptual framework of self-advocacy for students with disabilities', Remedial and Special Education, 26 (1), 43-54.

Thompson, L. A., Ferdig, R. \& Black, E. (2012) 'Online schools and children with special health and educational needs: comparison with performance in traditional schools', Journal of Medical Internet Research, 14 (2).

Unterhalter, E. (2009) 'What is equity in education? Reflections from the capability approach', Studies in Philosophy and Education, 28 (5), 415-424.

Vasquez, E. \& Straub, C. (2012) 'Online instruction for K-12 special education: a review of the empirical literature', Journal of Special Education Technology, 27 (3), 31-40.

Watson, J. (2007) 'A national primer on K-12 online learning', North American Council for Online Learning [online at http://files.eric.ed.gov/fulltext/ED509633.pdf].

Wehmeyer, M. L., Field, S., Doren, B., Jones, B. \& Mason, C. (2004) 'Self-determination and student involvement in standards-based reform', Exceptional Children, 70 (4), 413-425.

Wehmeyer, M. L. \& Garner, N. W. (2003) 'The impact of personal characteristics of people with intellectual and developmental disability on self-determination and autonomous functioning', Journal of Applied Research in Intellectual Disabilities, 16 (4), 255-265.

Weston, A. T. (ed.) (2009) Evaluating Online Learning: challenges and strategies for success. Hauppage, NY: Nova Science.

Wicks, M. (2010) 'A national primer on K-12 online learning', International Association for K- 12 Online Learning [online at https://net.educause.edu/ir/library/pdf/CSD6178.pdf]. 